\title{
A Comparison between Intrathecal Dexmedetomidine and Fentanyl as an Adjuvant to Hyperbaric Bupivacaine in Spinal Anaesthesia for Lower Limb Surgeries - A Double Blind Controlled Study
}

\author{
Gouranga Sikdar ${ }^{1}$, Rita Haldar (Dasgupta) ${ }^{2}$, Sujata Dalai ${ }^{3}$ \\ ${ }^{1} 3^{\text {rd }}$ Year MD Post Graduate Trainee, Department of Anaesthesiology, Medical College, Kolkata, West Bengal, India \\ ${ }^{2}$ Associate Professor, Dept of Anaesthesiology, Medical College, Kolkata,West Bengal, West Bengal, India \\ ${ }^{3}$ Assistant Professor, Dept of Anaesthesiology, Medical College, Kolkata, West Bengal, India
}

\begin{abstract}
Introduction: Various adjuvants have been used with local anesthetics in spinal anaesthesia to avoid intraoperative visceral and somatic pain and to provide prolonged postoperative analgesia. Dexmedetomidine, a highly selective a2 adrenergic agonist has evolved as a panacea for various applications and procedures in the perioperative and critical care setting. It is also emerging as a valuable adjunct to regional anaesthesia and analgesia, where gradually evolving studies can build the evidence for its safe use in central neuraxial blocks.Objectives: This study was aimed to evaluate the onset and duration of sensory and motor block, hemodynamic responses, postoperative analgesia, and adverse effects of dexmedetomidine or fentanyl when given intrathecally with hyperbaric bupivacaine. Methodology: 150 patients of ASA class I and II scheduled for lower limb surgeries were studied. Patients were randomly allocated to receive either $12.5 \mathrm{mg} 0.5 \%$ hyperbaric bupivacaine plus $5 \mu \mathrm{g}$ dexmedetomidine (Group $\mathrm{D}, \mathrm{n}=75$ ) or $12.5 \mathrm{mg} 0.5 \%$ hyperbaric bupivacaine plus $25 \mu \mathrm{g}$ fentanyl (Group $F, n=75)$ intrathecally. Results: Patients in Group $D$ had a significantly longer sensory and motor block time than patients in Group $F$. The sensory regression time to $S 1$ was $447.5 \pm 41.2 \mathrm{~min}$ in group $D$ and $179.9 \pm 20.14 \mathrm{~min}$ in group $F(P<0.0001)$. The time for rescue analgesia was $402.3 \pm 60.06 \mathrm{~min}$ in group $D$ and $150 \pm 29.6 \mathrm{~min}$ in group $F$ $(P<0.0001)$. Conclusion: Intrathecal dexmedetomidine is associated with prolonged motor and sensory block, hemodynamic stability, and reduced demand for rescue analgesics compared to fentanyl.
\end{abstract}

Keywords: Spinal anaesthesia, bupivacaine, adjuvant, dexmedetomidine, fentanyl

\section{Introduction}

Spinal block is still the first choice for lower limb surgeries because of its rapid onset, superior blockade, less failure rates and cost-effectiveness. ${ }^{[1]}$ Various drugs are used along with local anaesthetics to facilitate the prolongation of duration of spinal block both for long procedures and for postoperative pain relief. ${ }^{[2]}$

Intrathecal fentanyl exerts its effects by combining with opioid receptors in the dorsal horn of spinal cord and may have a supraspinal spread and action. Intrathecal fentanyl when added to spinal local anaesthetics reduces visceral and somatic pain. As fentanyl is lipophilic, the risk of respiratory depression is predominantly limited to the first $2 \mathrm{~h}$ after intrathecal injection; whereas intrathecal morphine has the risk of delayed respiratory depression due to rostral spread. $[3,4]$

Intrathecal $\alpha 2$ receptor agonists have antinociceptive action for both somatic and visceral pain. Dexmedetomidine shows more specificity towards $\alpha 2$ receptor ( $\alpha 2 / \alpha 1$ 1600:1) compared with clonidine ( $\alpha 2 / \alpha 1200: 1)^{[5]}$. Several studies have shown that $\alpha 2$ receptor agonists when administered intrathecally will enhance the analgesia provided by subtherapeutic doses of local anaesthetics like bupivacaine due to synergistic effects \& also minimal haemodynamic alteration. [6-8] Most of the clinical studies about the intrathecal $\alpha 2$ adrenergic agonist are related to clonidine. ${ }^{[8]}$

Based on earlier human studies, it is hypothesized that intrathecal $5 \mu \mathrm{g}$ dexmedetomidine would produce more postoperative analgesic effect with hyperbaric bupivacaine in spinal anaesthesia with minimal side effects. ${ }^{[9-12]}$

In view of few evidences of dexmedetomidine's efficacy as an adjuvant to hyperbaric bupivacaine in spinal anaesthesia, we carried out the study to explore its usefulness and also compare this new $\alpha 2$ adrenergic agonist with the previously established and widely used adjunct fentanyl on the spinal block characteristics in patients scheduled for lower limb surgery.

\section{Methodology}

This prospective double blinded randomised controlled study was conducted after having institutional ethical committee approval among 150 adult patients aged between 18-60 years of ASA Grade I \& II undergoing elective lower limb surgery under spinal anaesthesia in Green OT Complex \& Ortho OT complex, Dept. of Anaesthesiology; Medical College \& Hospital, Kolkata, West Bengal, during the period of January 2016 to June 2016. Sample size was calculated based on previous study, ${ }^{[13]}$ using the standard 


\section{International Journal of Science and Research (IJSR) \\ ISSN (Online): 2319-7064}

Index Copernicus Value (2015): 78.96 | Impact Factor (2015): 6.391

deviation of time to first analgesic request (TFAR). To detect a mean difference of $2 \mathrm{~h}$ between the groups in terms of TFAR with $\alpha=5 \%$ and $1-\beta=90 \%, 74$ patients per study group were needed. Hence, 75 patients were included in each group. So, total 150 patients comprised the study population.

The study population was randomly divided into 2 groups with 75 patients in each group-

Group D- patients were received $0.5 \%$ hyperbaric bupivacaine $12.5 \mathrm{mg}(2.5 \mathrm{ml})+$ diluted $5 \mu \mathrm{g}$ dexmedetomidine in $0.5 \mathrm{ml}$ preservative free normal saline.

Group F- patients were received 0.5\% hyperbaric bupivacaine $12.5 \mathrm{mg}(2.5 \mathrm{ml})+$ fentanyl $25 \mu \mathrm{g}(0.5 \mathrm{ml})$.

All patients were examined a day prior to surgery, and were familiarized with 'Numerical rating scale' (NRS) ${ }^{[14]}$ and its use for measuring the postoperative pain. Informed written consents were taken. They were advised for fasting for 6 hours for solid food and 2 hours for plain fluid. They were given tablet alprazolam $0.5 \mathrm{mg}$ as premedication a night before the day of the surgery. They were received tablet ranitidine $150 \mathrm{mg}$ one at previous night and another in the morning of the day of the surgery. In the operation theatre electrocardiogram (ECG), pulse oximetry, and noninvasive blood pressure were attached and baseline parameters were recorded. Intravenous line was secured with $18 \mathrm{G}$ cannula \& preloading with $10 \mathrm{ml} / \mathrm{kg}$ of lactated Ringer's was done to each patient. Under complete aseptic precautions lumbar puncture was performed at $\mathrm{L}_{3}-\mathrm{L}_{4}$ interspace using a $25 \mathrm{G}$ Quincke spinal needle with patient in sitting position. The study drug was injected into the subarachnoid space at a rate of $0.2 \mathrm{ml} / \mathrm{second}$ after noting the clear free flow of CSF ${ }^{[15]}$ with the operating table kept flat. Patients were turned supine immediately and were given supplemental oxygen 2L/min by nasal prong. Continuous monitoring of heart rate (HR), electrocardiogram (ECG), arterial oxygen saturation $\left(\mathrm{SaO}_{2}\right)$, and respiratory rate (RR) was done. Mean blood pressure (MBP) was recorded by non invasive blood pressure (NIBP) monitor every 3 min up to 15 min then every 5 min up to $90 \mathrm{~min}$ irrespective of the duration of the surgery. Hypotension was treated by injection mephentermine $3 \mathrm{mg}$ intravenous bolus and repeated as per requirement along with infusion of crystalloids. Heart rate (HR) less than 50 beats/min was corrected by using $0.6 \mathrm{mg}$ of intravenous atropine sulphate. ${ }^{[13]}$

The time to sensory block onset, highest level of sensory block, time to reach the highest dermatomal level were recorded. Two segment sensory regression time \& sensory regression time to S1 were also recorded. Motor block onset and duration of motor block was also recorded. The motor level was assessed according to modified Bromage score. Time for motor block onset was defined as modified Bromage score of 3 . Complete motor block recovery was assumed when modified Bromage score would be 0 . Surgery was allowed to commence on achieving adequate sensory block height (T10). Pain scores using numerical rating scale (NRS) was recorded 5 min before intrathecal injection, after the start of surgery, and subsequently every $10 \mathrm{~min}$ till the surgery is over; and thereafter pain was assessed in the postoperative period. Patients having NRS score more than or equal to 3 was administered intramuscular diclofenac $75 \mathrm{mg}$ as rescue analgesic along with Inj. Ranitidine 150mg i.v. The amount required by the patients in the next 24 hours was recorded. The incidence of pruritus, nausea, vomiting, and sedation were recorded. Other side effects and complications were also noted.

Data obtained was tabulated and analyzed using SPSS (version-20). Data was expressed as means and standard deviation (SD) or numbers and percentages. For categorical covariates like sex, ASA class, nausea/vomiting incidence, use of additive analgesia, hypotension, bradycardia etc., Chi square test was used, with $P$ value reported at the 95\% confidence interval (CI). Quantitative data was analyzed by student ' $\mathrm{t}$ ' test.

Hypotension was defined as SBP $<90 \mathrm{~mm} \mathrm{Hg}$ or $>30 \%$ fall from baseline. ${ }^{[11]}$ The onset of sensory block was defined as the time interval between injection of intrathecal anaesthetic and the absence of pain at the T10 dermatome; that was assessed by sterile pinprick every 2 min till T10 dermatome was achieved.

Ramsay sedation scale- ${ }^{[16]}$
\begin{tabular}{|l|l|}
\hline Score & Response \\
\hline 1 & Anxious or restless or both \\
\hline 2 & Cooperative, orientated and tranquil \\
\hline 3 & Responding to commands \\
\hline 4 & Brisk response to stimulus \\
\hline 5 & Sluggish response to stimulus \\
\hline 6 & No response to stimulus \\
\hline
\end{tabular}

\section{Results}

It was observed that majority of the patients i.e. $64 \%$ in Group D \& 69.33\% in Group F were male and the rest were female. The mean age was $42.28 \pm 15.22$ years for Group D and $41.81 \pm 11.26$ years for Group $F$. The mean BMI for Group D was $22.93 \pm 3.3 \mathrm{~kg} / \mathrm{m}^{2}$ and for Group F it was $23.21 \pm 2.76 \mathrm{~kg} / \mathrm{m}^{2}$. Majority of the patients were from ASA grade I i.e. $93.3 \%$ in Group D \& 90.7\% in Group F; 6.67\% patients of Group D and 9.3\% patients of Group F were from ASA II. [Table 1] Majority of patients in both the groups were undergone DHS surgery; $37.33 \%$ in Group D and $33.33 \%$ in Group F. Shaft femur ORIF was performed in $26.67 \%$ patients in Group D and in $30.67 \%$ patients in Group F. Other surgeries included 'Tibia ORIF', 'ACL reconstruction' and 'Malleolar fracture ORIF'. These two groups were comparable demographically by age, sex, weight, height, BMI, ASA grade and type of surgery. [Figure 1]

Table 1: Patient demographics

\begin{tabular}{|c|c|c|c|}
\hline & $\begin{array}{c}\text { Group D } \\
(\text { mean } \pm 2 \text { 2SD })\end{array}$ & $\begin{array}{c}\text { Group F } \\
(\text { mean } \pm 2 S D)\end{array}$ & P value \\
\hline Age (years) & $42.28 \pm 15.22$ & $41.81 \pm 11.26$ & $>0.05$ \\
\hline Sex ( M: F) & $16: 9$ & $11: 5$ & $>0.05$ \\
\hline Weight $(\mathrm{kg})$ & $62.08 \pm 12.78$ & $63.41 \pm 10.54$ & $>0.05$ \\
\hline Height $(\mathrm{cm})$ & $164.3 \pm 13.72$ & $165.3 \pm 10.02$ & $>0.05$ \\
\hline BMI $\left(\mathrm{kg} / \mathrm{m}^{2}\right)$ & $22.93 \pm 3.3$ & $23.21 \pm 2.72$ & $>0.05$ \\
\hline ASA I:II & $14: 1$ & $10: 1$ & $>0.05$ \\
\hline \multicolumn{4}{|c}{}
\end{tabular}




\section{International Journal of Science and Research (IJSR) \\ ISSN (Online): 2319-7064}

Index Copernicus Value (2015): 78.96 | Impact Factor (2015): 6.391

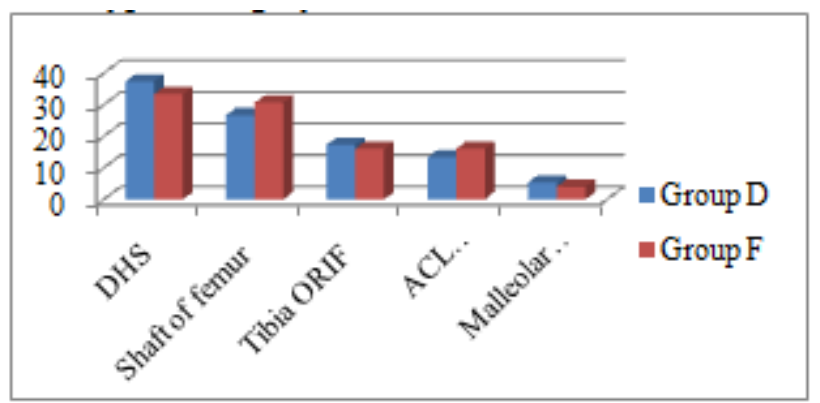

Figure 1: Type of surgery
The MAP was observed over time in both the groups. No significant differences were noted between the two groups. It was observed that there was an initial fall in MAP followed by a plateau then a gradual rise in MAP towards baseline in both the groups. The trend of heart rate (HR) was observed over time in both groups, though the HR in Group $\mathrm{D}$ was lower than Group F, but there were no significant differences between the two groups. It was observed that there was an initial rise of heart rate followed by gradual come down to base line in both groups. [Figure 2 \& 3]

[Data expressed as percentages, statistical method employed -chi square test, $\mathrm{p}$ value $>0.05$ - non significant]

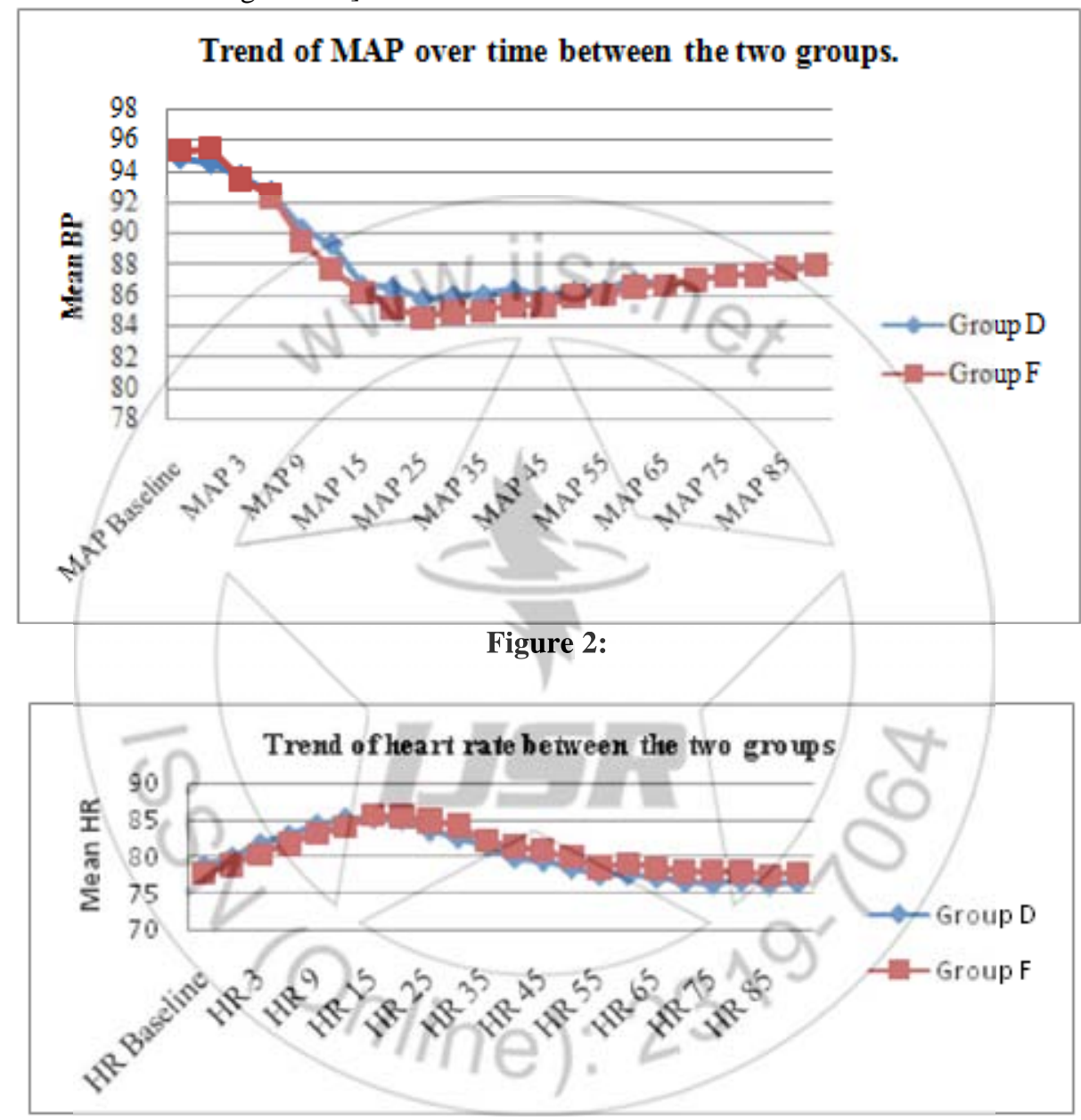

Figure 3:

The onset time for sensory block to T10 level in Group D was $9.75 \pm 2.6 \mathrm{~min}$, whereas it was $10.04 \pm 2.14 \mathrm{~min}$ in Group F. In majority of patients the highest level of sensory block was at T5 level i.e. $66.67 \%$ in Group D and $58.67 \%$ in Group F. Three patients (i.e. 4.0\%) of Group D and two (i.e. $2.67 \%$ ) patients of Group $F$ had highest level of sensory block of T4. In Group D, the time to reach the highest sensory level was $12.71 \pm 2.62 \mathrm{~min}$, where it was $13.01 \pm 2.36$ min in Group F. There were no significant differences in term of 'sensory block onset time' and 'highest level of sensory block' and the 'time to reach highest sensory level' between the two groups.

The time of two segment regression from highest sensory level was $138 \pm 19.92 \mathrm{~min}$ in Group D and $78 \pm 18.02 \mathrm{~min}$ in Group F. The regression time to S1 from highest sensory level for Group D was $447.5 \pm 41.2$ min and for Group F it was $179.9 \pm 20.14 \mathrm{~min}$. So, block regression was significantly slower with the addition of intrathecal dexmedetomidine (Group D) as compared with intrathecal fentanyl (Group F) to hyperbaric bupivacaine. ( $\mathrm{P}<0.0001)$ The motor onset time to 'modified Bromage 3' was $12.07 \pm 2.08 \mathrm{~min}$ in Group $\mathrm{D}$ and $12.0 \pm 2.28 \mathrm{~min}$ in Group F. The motor onset time was comparable between the two groups. The motor regression time to Bromage 0 for Group D was 401.1 \pm 47.02 min and for Group F it was $150.9 \pm 23.5 \mathrm{~min}$. There was significantly prolonged motor regression time for Group D compared to Group F. ( $\mathrm{P}<0.0001)$ The time when the patients first complained of pain in Group D was $402.3 \pm 60.06 \mathrm{~min}$, where in Group F it was $150.0 \pm 29.6 \mathrm{~min}$. The time when the patients first complained of pain in Group $\mathrm{D}$ was significantly higher compared to Group F patients. So, the

Volume 6 Issue 2, February 2017 


\section{International Journal of Science and Research (IJSR) \\ ISSN (Online): 2319-7064}

Index Copernicus Value (2015): 78.96 | Impact Factor (2015): 6.391

addition of intrathecal dexmedetomidine with hyperbaric bupivacaine prolonged the time when the patients first felt pain significantly compared to intrathecal fentanyl. [Table 2]

Table 2: Characteristics of spinal block

\begin{tabular}{|c|c|c|c|}
\hline & $\begin{array}{c}\text { Group D } \\
\text { (mean } \pm \text { 2SD) }\end{array}$ & $\begin{array}{c}\text { Group F } \\
\text { (mean } \pm 2 \text { SD) }\end{array}$ & P value \\
\hline $\begin{array}{c}\text { Time of onset of sensory } \\
\text { block (Target- T10) (min) }\end{array}$ & $9.75 \pm 2.60$ & $10.04 \pm 2.14$ & $>0.05$ \\
\hline $\begin{array}{c}\text { Highest sensory level } \\
\text { (dermatome) }\end{array}$ & $\begin{array}{c}\text { T5 (T4 } \\
\text { T8) }\end{array}$ & T5 (T4 - T8) & $>0.05$ \\
\hline $\begin{array}{c}\text { Time to reach highest } \\
\text { sensory level (min) }\end{array}$ & $12.71 \pm 2.62$ & $13.01 \pm 2.38$ & $>0.05$ \\
\hline $\begin{array}{c}\text { Time of two segment sensory } \\
\text { regression from highest level } \\
\text { (min) }\end{array}$ & $138 \pm 19.92$ & $78 \pm 18.02$ & $<0.0001$ \\
\hline $\begin{array}{c}\text { Time for sensory regression } \\
\text { to S1 from highest sensory } \\
\text { level (min) }\end{array}$ & $447 \pm 41.2$ & $179.9 \pm 21.4$ & $<0.0001$ \\
\hline $\begin{array}{c}\text { Time for rescue analgesia } \\
\text { (NRS 3) (min) }\end{array}$ & $402.3 \pm 60.06$ & $150 \pm 29.6$ & $<0.0001$ \\
\hline $\begin{array}{c}\text { Time of onset of motor } \\
\text { blockade (Bromage 3) }\end{array}$ & $12.07 \pm 2.08$ & $12 \pm 2.28$ & $>0.05$ \\
\hline $\begin{array}{c}\text { Time for regression to } \\
\text { Bromage 0 }\end{array}$ & $401.1 \pm 47.02$ & $150.9 \pm 23.5$ & $<0.0001$ \\
\hline
\end{tabular}

Majority of the patients i.e. $84.0 \%$ in Group D and $82.67 \%$ patients in Group $\mathrm{F}$ had sedation score of 2. 6.67\% patients in Group D and 9.33\% patients in Group F had sedation score of $1.9 .33 \%$ patients in Group D and $8.0 \%$ patients in Group F had sedation score of 3 . There were no significant differences in the term of sedation score between the two groups. [Table 3]

Table 3: Sedation score at one hour after spinal anaesthesia (Ramsay sedation scale)

\begin{tabular}{|c|c|c|c|}
\hline $\begin{array}{c}\text { Ramsay } \\
\text { Hunt scale }\end{array}$ & $\begin{array}{c}\text { Group F (n-75) } \\
\text { No.(\%) }\end{array}$ & $\begin{array}{c}\text { Group D (n-75) } \\
\text { No.(\%) }\end{array}$ & $\begin{array}{c}\text { Total } \\
\text { No.(\%) }\end{array}$ \\
\hline Score 1 & $5(6.67)$ & $7(9.33)$ & $12(8.0)$ \\
\hline Score 2 & $63(84.0)$ & $62(82.67)$ & $125(83.34)$ \\
\hline Score 3 & $7(9.33)$ & $6(8.0)$ & $13(8.67)$ \\
\hline Score 4 & - & - & - \\
\hline Score 5 & - & - & - \\
\hline Score 6 & - & - & - \\
\hline
\end{tabular}

Among the patients who faced side effects, $2.67 \%$ patients in Group D and 4.0\% patients in Group F had nausea. 8.0\% patients in Group D and $9.33 \%$ patients in Group $\mathrm{F}$ developed hypotension. $4.0 \%$ patients in Group D and 1.33\% patients in Group F developed bradycardia. 3.5\% patients in each group developed urinary retention. Only one patient $(1.33 \%)$ had pruritus in Group F. There were no significant differences by the incidence of side effects between the two groups. [Table 4]

Table 4: Incidence of side effects faced by the patient perioperatively

\begin{tabular}{|c|c|c|c|c|}
\hline Side effects & $\begin{array}{c}\text { Group } \\
\text { F (n-75) } \\
\text { No(\%) }\end{array}$ & $\begin{array}{c}\text { Group D } \\
(\mathrm{n}-75) \\
\text { No(\%) }\end{array}$ & $\begin{array}{c}\text { Total } \\
\text { No (\%) }\end{array}$ & P value \\
\hline Nausea & $2(2.67)$ & $3(4)$ & $5(3.33)$ & $>0.05$ \\
\hline Vomiting & - & $1(1.33)$ & $1(0.67)$ & $>0.05$ \\
\hline Pruritus & - & $2(3.5)$ & $2(1.33)$ & $>0.05$ \\
\hline $\begin{array}{c}\text { Respiratory } \\
\text { depression }\end{array}$ & - & - & - & - \\
\hline Hypotension & $6(8)$ & $7(9.33)$ & $13(8.67)$ & $>0.05$ \\
\hline
\end{tabular}

\begin{tabular}{|c|c|c|c|c|}
\hline Bradycardia & $3(4)$ & $1(1.33)$ & $4(2.67)$ & $>0.05$ \\
\hline Urinary retention & $2(3.5)$ & $2(3.5)$ & $4(2.67)$ & $>0.05$ \\
\hline Shivering & $2(3.5)$ & $3(4)$ & $5(3.33)$ & $>0.05$ \\
\hline
\end{tabular}

\section{Discussion}

This study was conducted to compare the efficacy, analgesic effects, and side effects of dexmedetomidine and fentanyl as adjuvant to hyperbaric bupivacaine for orthopaedic lower limb surgery. Sedation score was also assessed in both groups which have been reported in literature previously by only few studies. ${ }^{[17]}$

Time of onset of sensory block to T10 level was comparably similar in two groups. These finding was similar with Mahendru $\mathrm{V}$ et al ${ }^{[18]}$, who observed no difference in the onset time in patients receiving dexmedetomidine (10.3 \pm $3.3 \mathrm{~min})$ and fentanyl $(9.6 \pm 2.9)$ as adjuvant to hyperbaric bupivacaine and fentanyl $(7.4 \pm 3.3 \mathrm{~min})$ as adjuvants to isobaric bupivacaine $(P=0.95)$. Similarly, no significant differences in sensory onset time among study groups were also by observed by Gupta $\mathrm{R}$ et al, ${ }^{[12]}$ Kishore et al ${ }^{[19]}$ and Safari/et al. ${ }^{[20]}$ The onset times observed in the study conducted by AI Ghanem et al ${ }^{[10]}$ were relatively shorter by dexmedetomidine than those observed by us which can be attributed by difference in patient positioning (lithotomy vs supine in our study).

Highest sensory block level and the mean time to reach the highest sensory level were compared. No significant differences were noted between the two groups. Similar results were also noted by Kishore et al, ${ }^{[19]}$ Mehendru V et al, ${ }^{[18]}$ Gupta $\mathrm{R}$ et al. ${ }^{[21]}$ Motor block onset time to modified Bromage 3 was also observed but no statistically significant differences were found. Similar findings were noted by Gupta et al, Mehendru V et al. ${ }^{[18]}$ and Kishore et al. ${ }^{[19]}$

Heart rate (HR), mean arterial blood pressure (MAP) at baseline, just after dural puncture, at 3 min intervals till first $15 \mathrm{~min}$, then at $5 \mathrm{~min}$ intervals till $90 \mathrm{~min}$ were compared. Though there was theoretical possibility of lowering of HR ${ }^{\text {[22] }}$, difference of HR was not statistically significant at all the above intervals. Similar results were also observed by Khan et $\mathrm{al}^{[1]}$ Suresh et al, ${ }^{[23]}$ and Mahendru V et al ${ }^{[18]}$. Statistically significant lowering of HR was observed by Kishore et al ${ }^{\text {[19] }}$ in dexmedetomidine group compared to fentanyl group which may be attributed by their greater volume of intrathecal drugs (total $3.5 \mathrm{ml}$ compared to $3 \mathrm{ml}$ in our study). Similarly for MAP, no statistical significant difference was observed in our study between these two groups in above mentioned intervals. Similar observation was also noted by Mahendru $\mathrm{V}$ et al, ${ }^{[18]}$ Kishore et al, [19] and Gupta R et al. ${ }^{[21]}$

Two segment sensory regression from highest sensory block level, sensory block regression to S1 level and motor block regression to modified Bromage 0 was compared between this two groups. The differences for all this three parameters were very much statistically significant $(\mathrm{P}<0.0001)$. These findings clearly states that dexmedetomidine as an adjuvant provided prolonged sensory and motor duration compared to fentanyl as an adjuvant to hyperbaric bupivacaine. Similar findings was also observed by Khan et al ${ }^{[1]}$, Gupta $\mathrm{R}$ et al

\section{Volume 6 Issue 2, February 2017




\section{International Journal of Science and Research (IJSR) \\ ISSN (Online): 2319-7064}

Index Copernicus Value (2015): 78.96 | Impact Factor (2015): 6.391

[14], Mehendru V et al ${ }^{[18]}$, Kishore et al ${ }^{[19]}$, ], Safari et al ${ }^{[20]}$ Suresh et al. ${ }^{[23]}$, Sunil BV et al ${ }^{[24]}$, Nayagam HA et al ${ }^{[25]}$ and Routrey et al. ${ }^{[26]}$

The mechanism by which intrathecal $\alpha$ adrenoreceptor agonists prolong the motor and sensory block of local anaesthetics is at the best, speculative. It may be an additive or synergistic effect secondary to the different mechanisms of action of the local anaesthetics and intrathecal $\alpha$ adrenoreceptor agonists. Local anaesthetics act by blocking sodium channel and $\alpha$ adrenoreceptor agonists act by binding to the presynaptic $\mathrm{C}$ fibers and postsynaptic dorsal horn neurons. They produce analgesia by depressing release of $\mathrm{C}$ fiber transmitters and by hyperpolarization of post synaptic dorsal horn neurons. [27, 28] The complementary action of local anesthetics and $\alpha$ adrenoreceptor agonists accounts for their profound analgesic properties. The prolongation of the motor block of spinal anaesthetics may be the result of binding of $\alpha$ adrenoreceptor agonists to the motor neurons in the dorsal horn. Dexmedetomidine is eight times more specific and highly selective $\alpha$ adrenoreceptor agonists compared to clonidine, thereby making it a useful and safe adjunct in diverse clinical applications. [29]

We observed significantly delayed requirement of rescue analgesic with $5 \mu \mathrm{g}$ dexmedetomidine when compared with $25 \mu \mathrm{g}$ fentanyl, which supports the better analgesic efficacy of dexmedetomidine as an intrathecal adjunct. Similarly, significantly improved analgesic efficacy was seen by Kishore et al, ${ }^{[19]}$ Safari et al, ${ }^{[20]}$ Gupta et al, [21] Sunil BV et $\mathrm{al}^{[24]}$ and AI Mustafa et al. ${ }^{[30]}$ Dose dependent prolongation of motor and sensory blockade with reduced analgesic requirement with increasing dosages of intrathecal dexmedetomidine was observed by Dhimar AA et al. ${ }^{[31]}$

The most significant side effects reported about the use of intrathecal $\alpha$ adrenoreceptor agonists are bradycardia and hypotension. ${ }^{[22]}$ In the present study, these side effects were not significant probably because we used small dose of intrathecal dexmedetomidine with hyperbaric bupivacaine. Small dosages of adjuvants may also be responsible for minimal or no sedation observed in any of the groups in the study. The $15 \mu \mathrm{g}$ intrathecal dose of dexmedetomidine used by Hala EA et al, ${ }^{[32]}$ showed significantly higher sedation scores which can be beneficial for patients undergoing lengthy complex surgeries as an alternative to epidural or prolonged general anaesthetics and can preclude the use of IV sedatives. However, such high sedation scores may be harmful in elderly and high risk surgical patients owing to the risk associated with excessive sedation and respiratory depression. Pruritus after intrathecal fentanyl is known and was observed in a few patients but was not significant. Other side effects were comparable between these two groups. Comparable side effects were also observed by Khan et al, ${ }^{[1]}$ Safari et al, ${ }^{[20]}$ Gupta $r$ et al, ${ }^{[21]}$ and Suresh et al. ${ }^{[23]}$

\section{Conclusion \& Future Scope}

To conclude, our study report shows that the use of intrathecal dexmedetomidine at $5 \mu \mathrm{g}$ dose as an adjuvant to bupivacaine seems it to be an attractive alternative to fentanyl for surgical procedures. It provides good quality of intraoperative analgesia, haemodynamically stable conditions, minimal side effects, and excellent quality of postoperative analgesia without significant sedation. However, prolonged duration of motor blockade with dexmedetomidine may be undesirable for short term surgical procedures or ambulatory surgeries. Further research works are required to see the effect of dexmedetomidine in older patients with cardiovascular co morbidities.

\section{References}

[1] Khan AL SRTR. A comparative study between intrathecal dexmedetomidine and fentanyl as adjuvant to intrathecal bupivacaine in lower abdominal surgeries: A randomised trial. Anaestheia: Essays anf Research. 2015 Aug; 9: p. 139-48.

[2] Boussofara M CMRMSM. Effects of intrathecal midazolam on postoperative analgesia when added to a bupivacaine-clonidine mixture. Reg Anesth Pain Med. 2006; 31: p. 501-505.

[3] Fournier R VGWea. A comparison of intarthecal analgesia with fentanyl or sufentanyl after total hip replacement. Anaes Analg. 2000; 90: p. 918-22.

[4] Gustein HB AH. Goodamn and Gilman's the Pharmacological Basis of Therapeuitics. In Opioid Analgesics. 10th ed. New York: McGraw Hill; 2001. p. 595-96.

[5] Reves JG GPLDea. Miller's anaesthesia. In Livinstone C, editor. Intravenous anaesthesia.: Elsevier; 2015. p. 854.

[6] Dahlgren G HCJJea. Intrathecal sufenatanyl, fentanyl, or placebo added to bupivacaine for caesarean section. Anaes Analg. 1997; 85: p. 1288-93.

[7] Bajwa SJ AVKJea. Comparative evaluation of dexmedetomidine and fentanyl for epidural analgesia in lower limb orthopaedic surgeries. Saudi J Anaes. 2011; 5: p. 365-70.

[8] Elia N CMea. Clonidine as an adjuvant to intrathecal local anaesthetics for surgery: systematic reveiw randomised trials. Reg Anaes Pain Med. 2008; 33: p. 159-67.

[9] Kanazi Ge AMJKSea. Effect of low dose dexmedetomidine or clonidine on the characteristics of bupiovacaine spinal block. Acta Anaesthesiol Scand. 2006; 50: p. 222-27.

[10] Ghanem SM MIAMea. Effect of dexmedetomide versus fentanyl to intrathecal bupivacaine on spinal block characteristics in gynaecological procedures: A double blind controlled study. American Journal of Applied Sciences. 2009; 6: p. 882-7.

[11] Al Mustafa MM AHSAAea. Effect of dexmedetomidine added to spinal bupivacaine for urological procedures. Saudi Journal of Anaesthesia. 2009; 30: p. 365-70.

[12] Gupta R VRBJea. A comparative study of intrathecal dexmedetomidine and fentanyl as adjuvants to bupivacaine. Journal of Anaesthesia and Clinical Pharmacology. 2011; 27: p. 339-43.

[13] Kim SY CJKBKH. Comparison of intrathecal fentanyl and Sufentany in low-dose bupivacaine spinal anaesthesia for transurethral prostatectomy. British Journal of Anaesthesia. 2009; 103: p. 750.

[14] Katz J MR. Measurement of pain. Surg Clin North Am. 1999; 79: p. 231-52.

\section{Volume 6 Issue 2, February 2017}




\section{International Journal of Science and Research (IJSR) \\ ISSN (Online): 2319-7064 \\ Index Copernicus Value (2015): 78.96 | Impact Factor (2015): 6.391}

[15]Roland D MLIea. Miller's anaesthesia. 8th ed. lLivinstone C, editor. Philadelphia: Elsevier; 2015.

[16] Liu LL GM. Postoperative analgesia and sedation in adult intensive care unit. A guide to drug selection. Drugs. 2003; 63(8): p. 755-67.

[17] Jamliya R H DVRC. Intrathecal bupivacaine alone on spinal block characteristics in orthopaedic lower limb procedures[ A comparative study]. Journal of Pharmaceutical, Biological and Chemical Sciences. 2013 Jan-Mar; 4(1): p. 1340.

[18] Mahendru V TAKSGA. A comparison of intrathecal dexmedetomidine, clonidine, and fentanyl as adjuvants to hyperbaric bupivacaine for lower limb surgery: A double blind controlled study. J Anaesthesia Clin Pharmacol. 2013 Oct; 29(4).

[19] Kishore H POTT. A comparative study of intrathecal dexmedetomidine and fentanyl as adjuvants to bupivacaine for lower abdominal surgeries. Journal of Evidence based Medicine and Healthcare. 2015 Jan; 2(2): p. 124.

[20] Safari F ARMS. Intrathecal Dexmedetomidine and Fentanyl as Adjuvant to bupiovacaine on duration of spinal block in addicted patients. Anesth Painn Med. 2016 Feb; 6(1).

[21]Gupta R BJVR. Dexmedetomidine as an intrathecal adjuvant for postoperative analgesia. Indian $\mathrm{J}$ Anaesthesia. 2011 Jul-Aug; 55(4): p. 347-51.

[22] Philipp M BMHL. Physiological significance of alpha (2)-adrenergic receptor subtype diversity: One receptor is not enough. Am J Physiol Regul Integr Comp Physiol. 2002; 283: p. R287-95.

[23] Suresh G PC. A comparative study of intrathecal $0.5 \%$ hyperbaric bupivacaine with dexmedetomidine and $0.5 \%$ hyperbaric bupivacaine with fentanyl for lower abdominal surgeries. Sri Lankan Journal of Anaesthesiology. 2016; 34(1): p. 22-27.

[24] Sunil BV SK. Comparison of Dexmedetomidine, Fentanyl and Magnesium Sulfate as Adjuvants with Hyperbaric Bupivacaine for Spinal Anesthesia: A Double Blind Controlled Study. International Journal of Recent Trends in Science And Technology. 2013; 9(1): p. 14-19.

[25] Nayagam HA SN. A prospective randomised double blind study of intrathecal fentanyl and dexmedetomidine added to low dose bupivacaine for spinal anesthesia for lower abdominal surgeries. Indian journal of Anaesthesia. 2014; 58(4): p. 430-435.

[26] Routray S S RK. Effect of Intrathecal Dexmedetomidine and Fentanyl as Adjuvant to Hyperbaric Bupivacaine for Orthopaedic Lower Limb and Lower Abdominal Procedures: A Double Blind Control Study. Indian Journal of Clinical Anaesthesia. 2015; 2(4): p. 204-208.

[27] Carollo DS NBRU. Dexmedetomidine:A review of clinical applications. Curr Opin Anaesthesiol. 2008; 21: p. 457-61.

[28] Guo TZ JJBAMM. Dexmedetomidine injection into the locus ceruleus produces antinociception. Anesthesiology. 1996; 84: p. 873-81.

[29] A H. Intrathecal oioids in the management of acute postoperative piain. Continuing Education in Anaesthesia, critical care \& pain. 2008;(8): p. 81-85.
[30] Al-Mustafa MM ASAA. Effects of dexmedetomidine added to spinal bupivacaine for urological procedures. Saudi Med J. 2009;(30): p. 365-70.

[31]Dhimar A A LBKUMR. Dexmedetomidine as an adjuvant to intrathecal hyperbaric bupivacaine for spinal block characteristics and postoperative analgesia in lower limb orthopedic surgeries. Int J Res Med. 2015; 4(1): p. 77-83.

[32] Hala EA SMYH. Doserelated prolongation of hyperbaric bupivacaine spinal anesthesia by dexmedetomidine. Ain Shams J Anesthesiol. 2011; 4: p. 83-95. 